\title{
How much Sistan was successful in tuberculosis control?
}

\author{
A Sargazi ${ }^{1}$, Z Sepehri ${ }^{2 *}$, A Sargazi ${ }^{3}$, PK Nadakkavukaran $\mathrm{Jim}^{4}$, Z Kiani ${ }^{5}$ \\ From 3rd International Conference on Prevention and Infection Control (ICPIC 2015) \\ Geneva, Switzerland. 16-19 June 2015
}

\section{Introduction}

Tuberculosis (TB) is known as an infectious disease with high burden from a long time.

\section{Objectives}

Various strategies are implemented to control its spread in the world. Tuberculosis is controlled in Sistan by implementing Tuberculosis Control Program in Sistan (TCPS) and this study is to evaluate TCPS and Tuberculosis worker's role in it.

\section{Methods}

For this purpose we collected data with the methods of questionnaires, checklists, interviews, documentation review and observation. Using these methods together with data collection will boost the advantages of each single method. Effectiveness and efficiency considered as the priorities of TCPS evaluation. Data analyzed by using SPSS software.

\section{Results}

Current study showed in the first year of implementation they could run about $80 \%$ of the program quantitatively. The TB incidence was 94 and 107 per 100,000 of population respectively in 2011 and 2012 one year before and after TCPS implementation. The TCPS center reported 92.6\% and $88.4 \%$ of TB new cases in 2011 and 2012 respectively showed from the each dollar we spend in TCPS implementation, about 2 dollar was saved. The TCPS implemented $25 \%$ of WHO recommended strategies.

\section{Conclusion}

The total incidence increased one year after TCPS but the TCPS center and its workers' role in case reporting decreased. It could be related to more awareness in society or total TB growth and more preference and trust on private clinics. However there is no significant change in TB situation or patient destiny after TCPS implementation. The TCPS fail could be related to TB contact screen miss, its distance from World Health Organization procedures and health workers' role.

\section{Disclosure of interest}

None declared.

\section{Authors' details}

${ }^{1}$ Medical faculty, Zabol University of Medical Sciences, Zabol, Islamic Republic Of Iran. ${ }^{2}$ Research department, Zabol University of Medical Sciences, Zabol, Islamic Republic Of Iran. ${ }^{3}$ Civil faculty, Sistan and Baloochestan University, Zahedan, Islamic Republic Of Iran. ${ }^{4}$ Oracle eBusiness Department, Tech Mahindra, Linlithgow, UK. ${ }^{5}$ Medical faculty, Kerman Medical University, Kerman, Islamic Republic Of Iran.

Published: 16 June 2015

\section{References}

1. Lönnroth K, Raviglione M: Global epidemiology of tuberculosis: prospects for control. In Seminars in respiratory and critical care Medicine. Thieme Medical Publishers; 2008:29(5):481-491.

2. Atun R, Lennox-Chhugani N, Drobniewski F, Samyshkin Y, Coker R: A framework and toolkit for capturing the communicable disease programmes within health systems tuberculosis control as an illustrative example. The European Journal of Public Health 2004, 14(3):267-273.

doi:10.1186/2047-2994-4-S1-P101

Cite this article as: Sargazi et al:: How much Sistan was successful in tuberculosis control? Antimicrobial Resistance and Infection Control 2015 4(Suppl 1):P101.

${ }^{2}$ Research department, Zabol University of Medical Sciences, Zabol, Islamic Republic Of Iran

Full list of author information is available at the end of the article 